\title{
A Simple Neoclassical Point Model for Transport and Scaling in EBT
}
C. L. Hedrick
E. F. Jaeger
D. A. Spong
G. E. Guest
N. A. Krall
J. B. McBride
G. W. Stuart

\section{OAK RIDGE NATIONAL LABORATORY}




\section{DISCLAIMER}

This report was prepared as an account of work sponsored by an agency of the United States Government. Neither the United States Government nor any agency Thereof, nor any of their employees, makes any warranty, express or implied, or assumes any legal liability or responsibility for the accuracy, completeness, or usefulness of any information, apparatus, product, or process disclosed, or represents that its use would not infringe privately owned rights. Reference herein to any specific commercial product, process, or service by trade name, trademark, manufacturer, or otherwise does not necessarily constitute or imply its endorsement, recommendation, or favoring by the United States Government or any agency thereof. The views and opinions of authors expressed herein do not necessarily state or reflect those of the United States Government or any agency thereof. 


\section{DISCLAIMER}

Portions of this document may be illegible in electronic image products. Images are produced from the best available original document. 
Printed in the United States of America. Available from National Technical Information Service

U.S. Department of Commerce

5285 Port Royal Road, Springfield, Virginia 22161

Price: Printed Copy $\$ 4.00 ;$ Microfiche $\$ 3.00$

This report was prepared as an account of work sponsored by the United States Government. Neither the United States nor the Energy Research and Development Administration/United States Nuclear Regulatory Commission, nor any of their employees, nor any of their contractors, subcontractors, or their employees, makes any warranty, express or implied, or assumes any legal liability or responsibility for the accuracy, completeness or usefulness of any information, apparatus, product or process disclosed, or represents that its use would not infringe privately owned rights. 
Contract No. W-7405-eng-26

FUSION ENERGY DIVISION

A SIMPLE NEOCLASSICAL POINT MODEL FOR

TRANSPORT AND SCALING IN EBT

C. L. Hedrick, E. F. Jaeger, D. A. Spong

Oak Ridge National Laboratory, Oak Ridge, Tennessee 37830

G. E. Guest

General Atomic Company, San Diego, California 92138

N. A. Krall, J. B. McBride and G. W. Stuart

Science Applications, Inc., La Jolla, California 92037

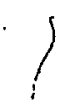

(As submitted to Nuclear Fusion by Science Applications, Inc.)

Date Published - April 1977

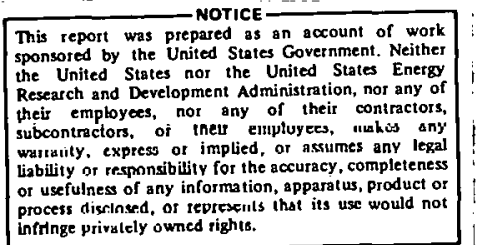

This report was prepared as an account of work sponsored by the United States Goved States Energy Research and Development Administration, nor any of Wheir employees, nor any of their contras intringe privalely owned rights.

NOTICE This document contains information of a preliminary nature. $1 t$ is subject to revision or eorrection and thereforo doos not roprecent a final report.

\author{
OAK RIDGE NATIONAL LABORATORY \\ Oak Ridge, Tennessee 37830 \\ operated by \\ UNION CARBIDE CORPORATION \\ for the \\ ENEROY RESEARCH AND DEVELOPMENT ADMINISTRATION
}

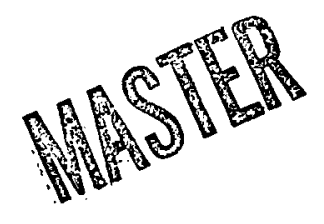


THIS PAGE

WAS INTENTIONALLY

LEFT BLANK 


\title{
A SIMPLE NEOCLASSICAL POINT MODEL FOR
} TRANSPORT AND SCALING IN EBT*

\author{
C. L. Hedrick, E. F. Jaeger, D. A. Spong \\ Oak Ridge National Laboratory, Oak Ridge, Tennessee 37830 \\ G. E. Guest
}

General Atomic Company, San Diego, California 92138

N. A. Krall, J. B. McBride and G. W. Stuart

Science Applications, Inc., La Jolla, California 92037

\begin{abstract}
A simple neoclassical point model is presented for the ELMO Bumpy Torus experiment. Solutions for steady state are derived. Comparison with experimental observations is made and reasonable agreement is obtained.

* Work supported by Energy Research and Development Administration
under Contract W-7405-eng-26 with Union Carbide Corporation,
Contract EY-76-C-03-0167, Project 38 with General Atomic Company,
and Contract AT-04-3-1018 with Science Applications, Incorporated.
\end{abstract}




\section{INTRODUCTION}

Here we consider a simple neoclassical point model for transport and scaling in the ELMO Bumpy Torus (EBT). Steady-state solutions are found which are in reasonable accord with experimental observations. Several modes of operation are observed in EBT and this model is only meant to apply to the most interesting regime of operation. Thus we begin by summarizing the pertinent features of the experimental results. 1

The EBT is a plasma confinement device consisting of a set of magnetic mirror, sections linked in a torus. A central element of the EBT concept is the presence of a hot electron annulus in each mirror section," of sufficient density and temperature that diamagnetic plasma currents produce a minimum in the magnetic field. Without such a minimum, theory would predict macroscopic instability. Experimentally a rather cold and noisy mode of operation is observed when insufficient microwave power is supplied to produce substantial annular beta (ratio of plasma pressure to magnetic pressure). A rather abrupt transition from the cold or C-mode of operation to a quiet state is observed when the annular beta exceeds a critical value ( $5 \%$ to $15 \%)$. This value of beta corresponds to theoretical estimates of the beta necessary to produce a well defined minimum in the magnetic field. 'I'his quiet 
mode of operation has a substantial toroidal plasma and is termed the $\mathrm{T}$-mode. The model presented here is for the $\mathrm{T}$-mode.

The $\mathrm{T}$-mode is a steady-state plasma; with neutral particles entering the torus and being ionized at the same rate at which plasma is lost by diffusion. As the neutral particle density is lowered, a second abrupt transition occurs, from the $\mathrm{T}$-mode to the $\mathrm{M}$-mode. In the mirror or $\mathrm{M}$-mode, the individual sectors (or bumps) of the torus behave rather like disconnected simple mirror machines. The hot electron annular beta becomes quite large and the toroidal plasma all bul vanishes.

Both theoretically and experimentally a radial ambipolar electric field arises to equalize electron and ion diffusion losses. This radial field, $E$, in the $T$-mode is such that $e \varphi / T_{i}$ is of order unity. Thus the bulk of the ions have energies below a few times the ambipolar potential energy. This has important consequences on single particle drift motion and hence upon neoclassical losses. The motion of particles with energies below the ambipolar potential energy are dominated by $E \times B$ drifts. The drift motion of high energy particles is dominated by gradient $B$ and curvature drifts (proportional to particle energy). 
There are two important neoclassical particle loss mechanisms associated with drift orbits. The first of these is particles drifting directly to the walls due to the toroidal curvature drifts of particles, which because of their location in velocity space, do not sample the entire EBT geometry (unconfined orbits). The electric field can affect this loss mechanism by moving the "loss zone" to higher energy portions of velocity space which are sparsely populated. The second mechanism is neoclassical diffusion. This mechanism depends upon scattering in velocity space and dispersion in the particle drift orbits. Since much of the distribution has its motion dominated by the $\mathrm{E} \times \mathrm{B}$ drift, this loss mechanism is also affected.

Experimentally the electric field appears to be strongest in the vicinity of the annulus so that the following picture emerges. Exterior to the annuli, the losses are dominated by particles moving directly to the walls. Interior to the annuli, diffusive transport losses dominate. It is for this central toroidal core that our model applies.

Within the toroidal core the ions are reasonably approximated by a fluid description in which Coulomb collisions provide the scattering mechanism. The electrons' behavior on the other hand, may be more complex. One reason for this is that the hot-electron annulus overlaps this central region. Thus we have a mirror confined, high energy tail on the distribution which could alter the usual neoclassical transport coefficients calculated for a Maxwell distribution. Also the microwave 
electric field may provide a significant source of scattering in velocity space in addition to Coulomb collisions, although a rigorous theory of this process is presently lacking. In this paper, we ignore these complexities, assume that the dominant electron losses are neoclassical and equate the theoretical expressions for the ion and electron loss rates. The electric field is then calculated and used to determine a single, selfconsistent neoclassical, ambipolar loss rate. The success of this fully neoclassical model in predicting energy balance consistent with observation indicates the validity of our assumption.

II. EBT MODEL EQUATIONS

In this section we present the equations for the plasma density, n, and the toroidal core ion and electron temperatures, $\mathrm{T}_{\mathrm{i}}$ and $\mathrm{T}_{\mathbf{e}}$ : The spatial dependence is eliminated by replacing all plasma gradients by characteristic scale lengths equal to the plasma minor radius, $a=-(d / d x)^{-1}$. Since all transport coefficients have the same functional form we define a single confinement time taken to be the particle ambipolar diffusion time. 
The equations are:

$$
\begin{gathered}
\frac{d n}{d t}=n\left(n_{o}\langle\sigma v\rangle_{\text {ioniz }}-\tau^{-1}\right) \\
\frac{d}{d t}\left(\frac{3}{2} n T_{i}\right)=P_{e i}-\frac{3}{2} n T_{i}\left(n_{o}\langle\sigma v\rangle_{c x}+\tau^{-1}\right) \\
\frac{d}{d t}\left(\frac{3}{2} n T_{e}\right)=P_{\mu}-P_{e i}-\frac{3}{2} n T_{e} \tau^{-1}
\end{gathered}
$$

Here $\mathrm{n}_{\mathrm{O}}$ is the neutral particle density and $\mathrm{n}_{\mathrm{O}}\left\langle\sigma_{\mathrm{V}}\right\rangle_{\text {ioniz }}$ and $\mathrm{n}_{\mathrm{o}}\left\langle\sigma_{\mathrm{V}}\right\rangle_{\mathrm{cx}}$ are the ionization and charge exchange rates. The neoclassical particle diffusion rates, based on the work of Kovrizhnikh ${ }^{2}$ and Harris, ${ }^{3}$ are taken to be

$$
\begin{gathered}
\tau_{\alpha}^{-1}=\left(1 \mathrm{D}_{\alpha} / \mathrm{a}^{2}\right)\left(1+\mathrm{q}_{\alpha} \mathrm{a} \mathrm{E} \cdot \mathrm{T}_{\alpha}\right) \\
\mathrm{D}_{\alpha}=\frac{\mathrm{a}^{2}}{3}\left(\frac{\mathrm{Rc}}{\mathrm{R}_{\mathrm{T}}}\right)^{2} \frac{\nu_{\alpha}}{\mathrm{y}_{\alpha}} 2 \frac{1}{\left(1+\nu_{\alpha}^{2}, \mathrm{y}_{\alpha}{ }^{2} \Omega_{\mathrm{\Omega}}^{2}\right)}
\end{gathered}
$$


where $\alpha=e, i$ refers to electrons, ions. The collision frequencies are

$$
\begin{gathered}
v_{\mathrm{i}}=\mathrm{C}_{1} \mathrm{n} / \mathrm{T}_{\mathrm{i}}^{\frac{2}{2}} ; \quad \mathrm{C}_{1}=\left(\frac{\mathrm{e}^{2}}{\varepsilon_{\mathrm{o}}}\right)^{2} \frac{\ln \Lambda}{25.8 \sqrt{\pi \mathrm{M}_{\mathrm{i}}}} \\
v_{\mathrm{e}}=\left(\mathrm{T}_{\mathrm{i}} / \mathrm{T}_{\mathrm{e}}\right)^{\frac{3}{2}}\left(\mathrm{M}_{\mathrm{i}} / \mathrm{m}_{\mathrm{e}}\right)^{\frac{1}{2}} \nu_{\mathrm{i}}
\end{gathered}
$$

and the average poloidal curvature drift frequencies are given by

$$
\Omega_{O \alpha}=\left(\frac{T_{\alpha}}{q_{\alpha} R_{c}^{a}}\right)
$$

and

$$
y_{\alpha}=1+\frac{q_{\alpha}^{j} E R_{c}}{T_{\alpha}} .
$$

Notice that $\Omega_{0} \mathrm{y}$ incorporates the gradient-B and curvature drifts through the mirror radius of curvature, $R_{c}$, and the $E \times B$ drift through the parameter $y \cdot R_{T}$ is the toroidal or major radius of the plasma.

The $E \times B$ drift from a positive electric field increases the ion poloidal drift frequency and decreases it for the electrons.

The transfer of energy from electrons to ions via Coulomb collisions is given by 


$$
\mathrm{P}_{\mathrm{ei}}=\mathrm{C}_{2} \frac{\mathrm{n}^{2}}{\mathrm{~T}_{\mathrm{e}}^{\frac{1}{2}}}\left(1-\frac{\mathrm{T}_{\mathrm{i}}}{\mathrm{T}_{\mathrm{e}}}\right) ; \mathrm{C}_{2}=\left(\frac{\mathrm{e}^{2}}{\varepsilon_{\mathrm{o}}}\right)^{2} \frac{\sqrt{\mathrm{m}_{\mathrm{e}}}}{\mathrm{M}_{\mathrm{i}}} \frac{\ln \Lambda}{(2 \pi)^{\frac{2}{2}}}
$$

The microwave power per unit volume absorbed by the toroidal core electrons is denoted by $\mathrm{P}_{\mu}$, and we will find it convenient to define a reactivity

$$
S_{c x} \equiv 1+\left\langle\sigma_{v}\right\rangle_{c x} /\left\langle\sigma_{v}\right\rangle_{\text {ioniz }}
$$

\section{STEADY-STATE SOLUTIONS}

We now set the time derivatives to zero in Eqs. (1) - (3) to obtain the steady-state solutions. The time dependent equations can properly be regarded as equations for $n, T_{i}$ and $T_{e}$ in terms of the independent variables $\mathrm{n}_{0}$ and $\mathrm{P}_{\mu}$. The solution of the (algebraic) steady-state equations is facilitated by interchanging the role of dependent and independent variables. In particular we regard $n_{0}$ as a dependent variable and introduce a new independent variable

$$
\mathrm{X}=\mathrm{T}_{\mathrm{e}} / \mathrm{T}_{\mathrm{i}}
$$


Setting the time derivative to zero in Eq. (1) yields

$$
\mathrm{n}_{\mathrm{o}}=1 /\left(\tau\left\langle\sigma_{\mathrm{v}}\right\rangle_{\text {ioniz }}\right)
$$

Using this expression to eliminate the neutral density from Eq. (2) and setting the time derivatives to zero in Eqs. (2) and (3) gives the following power balance

$$
\begin{aligned}
& \mathrm{P}_{\text {ei }}=\frac{3}{2} \frac{{ }^{n T} \mathrm{i}_{\mathrm{i}}}{\tau} \mathrm{S}_{\mathrm{cx}} \\
& \mathrm{P}_{\mu}=\mathrm{P}_{\mathrm{ei}}+\frac{3}{2} \frac{\mathrm{nT} \mathrm{e}}{\tau}
\end{aligned}
$$

Using Eq. (9) for $\mathrm{P}_{\text {ei }}$, Eq. (13) becomes

$$
\tau=\left(\frac{3}{2} \frac{s_{c x}}{C_{2}}\right) \frac{T_{e}^{\frac{3}{2}}}{n(X-1)}
$$

Now substituting for $P_{p i}$ in Eq. (14) and using Eq. (15), we obtain a relation between $\mathrm{n}, \mathrm{T}_{\mathrm{e}}, \mathrm{P}_{\mu}$, and $\mathrm{X}$ which can be written as:

$$
T_{e}=Q^{2} n^{4} / P_{\mu}^{2}
$$


where

$$
Q \equiv\left(\frac{C_{2}}{S_{c x}}\right) \frac{(X-1)\left(X+S_{c x}\right)}{X}
$$

Equation (16) may now be used to eliminate $\mathrm{T}_{\mathrm{e}}$ from Eq. (15) with the result

$$
\tau=\left(\frac{3}{2} \frac{\mathrm{S}_{\mathrm{cx}}}{\mathrm{C}_{2}}\right) \frac{\mathrm{Q}^{3}}{\mathrm{X}-1} \frac{\mathrm{n}^{5}}{\mathrm{P}_{\mu}^{3}}
$$

We now make our first use of the explicit expressions for the neoclassical lifetimes, Eq. (4). As discussed in the introduction, neoclassical theory is used to calculate both electron and ion loss rates, and the ambipolar field is calculated from the condition that these rates be equal.

The following interesting relationships follow from ambipolarity

$$
E=\frac{T_{e}}{e a}\left(\frac{D_{e}-D_{i}}{D_{e}+X D_{i}}\right)
$$




$$
\begin{aligned}
\tau^{-1} & =\frac{4(1+\mathrm{X})}{\mathrm{a}^{2}}\left(\frac{\mathrm{D}_{\mathrm{i}}}{1+\mathrm{X} \frac{\mathrm{D}_{\mathrm{i}}}{\mathrm{D}_{\mathrm{e}}}}\right) \\
\mathrm{D}_{\mathrm{i}} / \mathrm{D}_{\mathrm{e}} & =\left(1-\mathrm{eEa} \cdot \mathrm{T}_{\mathrm{e}}\right) /\left(1+\mathrm{eEa} / \mathrm{T}_{\mathrm{i}}\right)
\end{aligned}
$$

These formal relationships are similar to those obtained in the problem of classical diffusion in weakly ionized gases, but here the diffusion coefficients themselves depend on the electric field. From Eq. (21) and the definition of $D_{\alpha}\left(D_{\alpha}\right.$ is positive definite) we see that the ambipolar electric field is bounded as

$$
-\mathrm{T}_{\mathrm{i}}<\mathrm{eEa}<\mathrm{T}_{\mathrm{e}}
$$

In addition we see from Eqs. (19) and (20) that for highly mobile electrons, i.e., $\mathrm{D}_{\mathrm{e}} \gg \mathrm{X}_{\mathrm{i}}$; the electric field is approximately 


$$
\mathrm{E} \simeq \frac{\mathrm{T}_{\mathrm{e}}}{\mathrm{ea}}
$$

and the containment time is determined by the ion diffusion rate in this field.

$$
\tau^{-1} \simeq \frac{4(1+\mathrm{X})}{\mathrm{a}^{2}} \mathrm{D}_{\mathrm{i}}\left(\mathrm{E} \simeq \mathrm{T}_{\mathrm{e}}^{\prime} \mathrm{ea}\right)
$$

Experimentally measured electric fields at the plasma periphery ${ }^{1}$ in $\mathrm{T}$-mode operation are of the same sign and comparable magnitude to that in Eq. (23). Note that $D_{e}>D_{i}$ is required for positive $\mathrm{E}$. It is shown below using numerical solutions of the exact equations that this $\left(D_{e}>X D_{i}\right)$ branch of the multivalued equilibrium corresponds to experimental observation. Other branches have negative $E$ or $T_{e} \gg T_{i}$. Thus before proceeding to a more exact analysis of the ambipolar equilibrium, it is instructive to examine the equilibrium predicted by Eqs. (23), (24). Substituting Eq. (24) into Eq. (13) and using Eqs. (5), (6), (8) and (9), we find 


$$
\frac{(\mathrm{X}-1)}{\mathrm{X}^{\frac{3}{2}}} \frac{\left(1+\mathrm{X}_{\mathrm{c}} \mathrm{R}_{\mathrm{a}}\right)^{2}}{(1+\mathrm{X})}=0.69\left(\mathrm{M}_{\mathrm{i}} / \mathrm{m}_{\mathrm{e}}\right)^{1 / 2} \frac{\left(\mathrm{R}_{\mathrm{c}} / \mathrm{R}_{\mathrm{T}}\right)^{2} \mathrm{~S}_{\mathrm{cx}}}{\left[1+\frac{\nu_{\mathrm{i}}^{2}}{S_{\mathrm{O} i}^{2}}\left(1+\mathrm{X} \mathrm{R}_{\mathrm{c}} / \mathrm{a}\right)^{-2}\right]}
$$

Thus collisionless operation, which is actually the limit in which Eq.

(23) is the approximate ambipolar field, determines $\mathrm{X}$ for a given aspect ratio. Equation (16) and (18) can then be used to determine $\mathrm{T}_{\mathrm{e}}$ and $\tau$ for a given density and $P_{H}$, and $T_{i}=T_{e} / X$ completes the explicit analytic solution of the power balance equations in this limit. Note the favorable scaling $T_{e} \sim n^{4}, \tau \sim n^{5}$ for fixed $X$. For present EBT, Eq. (25) predicts $X \simeq 1.3$, if the collisionless ion limit were attained, assuming $S_{c x}=2$. Further if we assume $F_{\mu t}=5 \times 10^{-3} \mathrm{~W} / \mathrm{cm}^{3}$ (about $1 / 5$ the total power input) then at $\mathrm{n}=3 \times 10^{12} \mathrm{~cm}^{-3}, \tau=27 \mathrm{msec}$, $\mathrm{T}_{\mathrm{i}}=60 \mathrm{eV}, \mathrm{T}_{\mathrm{e}}=80 \mathrm{eV}$. This is consistent with present experimental estimates of density, ion temperature and containment time but is too low for the electron temperature. As we shall see, a more accurate numerical treatment brings the neoclassical point model into better overall agreement with experiment.

Setting $\tau_{\mathrm{i}}=\tau_{\mathrm{e}}$ using Eq. (4) we obtain the following cubic equation for $E$ 


$$
\begin{gathered}
{\left[\left(1+\frac{e \mathrm{R}_{\mathrm{c}}{ }^{2}}{\mathrm{~T}_{\mathrm{i}}}\right)^{2}+\frac{\nu_{\mathrm{i}}^{2}}{\Omega_{\mathrm{oi}}^{2}}\right]\left(\frac{\mathrm{eaE}}{\mathrm{T}_{\mathrm{e}}}-1\right)+\left[\left(1-\frac{\mathrm{eR}_{\mathrm{c}} \mathrm{E}^{2}}{\mathrm{~T}_{\mathrm{e}}}\right)^{2}+\frac{\nu_{\mathrm{e}}^{2}}{\Omega^{2}}\right]} \\
\cdot \sigma^{\frac{1}{2}} \mathrm{x}^{\frac{3}{2}}\left(\frac{\mathrm{eEa}}{\mathrm{T}_{\mathrm{i}}}+1\right)=0
\end{gathered}
$$

where $\delta \equiv \mathrm{m}_{\mathrm{e}} / \mathrm{m}_{\mathrm{i}}$. For possible future reference we note that in deriving Eq. (26) no use has been made of the steady state limit $(d / d t=0)$ of Eqs. (1) - (3). Thus these four equations can be used to study the time evolution of EBT, although this is not done in the present paper. We notice that Eq. (26) does indeed have the approximate solution Eq. (23) in the (collisionless) limit $\left(v_{\mathrm{e}}^{2} / \Omega_{\mathrm{oe}}^{2}\right) \delta^{\frac{1}{2}} \mathrm{X}^{\frac{3}{2}} \ll 1$. Equations (26), (13) - (15) are a coupled set of equations for $n, T_{e}, T_{i}, E$. It is convenient to solve them by using Eq. (15) with $\tau=\tau_{\mathrm{i}}$, with Eq. (26) guaranteeing that $\tau_{\mathrm{i}}=\tau_{\mathrm{e}}$, to generate an independent quadratic equation for $E$.

$$
\left(1+\frac{\mathrm{eR}_{\mathrm{c}} \mathrm{E}}{\mathrm{T}_{\mathrm{i}}}\right)^{2}+\frac{\nu_{\mathrm{i}}^{2}}{\Omega_{\mathrm{oi}}^{2}}=\left(1+\frac{\mathrm{eaE}}{\mathrm{T}_{\mathrm{i}}}\right) \quad 2 \mathrm{~S}_{\mathrm{cX}} \frac{\mathrm{C}_{1}}{\mathrm{C}_{2}}\left(\frac{\mathrm{R}_{\mathrm{c}}}{\mathrm{R}_{\mathrm{T}}}\right)^{2} \frac{\mathrm{X}^{\frac{3}{2}}}{(\mathrm{X}-1)}
$$


Solving Eq. (27) for $\nu_{i}^{2} / \Omega_{o i}^{2}$ and noting from Eqs. (6) and (7) that

$$
-\frac{\nu_{\mathrm{e}}}{\Omega_{\mathrm{oe}}}=\frac{\nu_{\mathrm{i}}}{\Omega_{\mathrm{oi}}} \frac{1}{\sqrt{\delta \mathrm{X}^{5}}}
$$

we may substitute into $\mathrm{Eq}$. (26) to obtain an equation for $\mathrm{E} / \mathrm{T}_{\mathrm{i}}$ in terms of $\mathrm{X}$. Note the occurence of the common factor $\left(1+\mathrm{eEa} / \mathrm{T}_{\mathrm{i}}\right)$. when we do this. We neglect this negative root as unphysical. 'The ' remaining roots for $\mathrm{E} / \mathrm{T}_{\mathrm{i}}$ satisfy

$$
\begin{gathered}
\left(1+\frac{e \mathrm{R}_{c} \mathrm{E}}{\mathrm{T}_{\mathrm{i}}}\right)^{2}-\delta \mathrm{x}^{5}\left(1-\frac{\mathrm{eR} \mathrm{c}^{\mathrm{E}}}{\mathrm{T}_{\mathrm{e}}}\right)^{2}-2 \mathrm{~S}_{\mathrm{cx}} \frac{\mathrm{C}_{1}}{\mathrm{C}_{2}}\left(\frac{\mathrm{R}_{\mathrm{c}}}{\mathrm{R}_{\mathrm{T}}}\right)^{2} \cdot \frac{\mathrm{x}^{\frac{3}{2}}}{(\mathrm{X}-1)} \\
\therefore \\
\cdot\left[1, \frac{\mathrm{eEa}}{\mathrm{T}_{\mathrm{i}}}+\delta^{1 / 2} \mathrm{x}^{\frac{1}{2}}\left(\frac{\mathrm{eEa}}{\mathrm{T}_{\mathrm{e}}}-1\right)\right]=0
\end{gathered}
$$


Finally we utilize Eqs. (6), (7) and (16) to write

$$
\frac{\nu_{i}}{\Omega_{o i}}=\frac{C_{1} e B c_{c} P_{\mu}^{5}}{Q^{5}} \cdot \frac{X^{5 / 2}}{n^{9}}
$$

Substituting this expression into Eq. (27) we obtain:

$$
n^{18}=P_{\mu}^{10} \frac{\left(C_{1} e B R_{c} a\right)^{2}}{Q^{10}} x^{5}
$$

- $\left\{2 \mathrm{~S}_{\mathrm{cx}} \frac{\mathrm{C}_{1}}{\mathrm{C}_{2}}\left(\frac{\mathrm{R}_{\mathrm{c}}}{\mathrm{R}_{\mathrm{T}}}\right)^{2} \frac{\mathrm{x}^{\frac{3}{2}}}{\mathrm{X}-1}\left(1+\frac{\mathrm{eEa}}{\mathrm{T}_{\mathrm{i}}}\right)-\left(1+\frac{\mathrm{eR}_{\mathrm{c}} \mathrm{E}}{\mathrm{T}_{\mathrm{i}}}\right)^{2}\right\}^{-1}$

We now have expressions for all the relevant quantities as functions of $\mathrm{X}$. The procedure is to solve $\mathrm{Eq}$. (28) for $\mathrm{E} / \mathrm{T}_{\mathrm{i}}$ as a function of $\mathrm{X}$. From Eq. (29) we then obtain the density. From Eq. (16) we obtain $T_{e}$ and hence $\mathrm{T}_{\mathrm{i}}$ from $\mathrm{T}_{\mathrm{i}}=\mathrm{T}_{\mathrm{e}} / \mathrm{X}$. The lifetime is obtained from $\mathrm{Eq}$. (18) and the neutral density from Eq. (12).

The density in EBT appears to be limited by microwave cutoff. Thus in the next section we cross-plot the results versus density. We. also restrict our attention to positive electric fields as inferred from measurement at the plasma periphery. ${ }^{1}$ 
IV. COMPARISON WITH EXPERIMENTAL RESULTS

In this section we present numerical results for comparison with experiment. For all the calculations presented here we have taken:

$$
\begin{aligned}
\mathrm{B} & =0.65 \text { Tesla } \\
\mathrm{R}_{\mathrm{T}} & =1.5 \mathrm{~m} \\
\mathrm{R}_{\mathrm{c}} & =0.188 \mathrm{~m} \\
\mathrm{a} & =0.1 \mathrm{~m} \\
\ln \Lambda & =17 \\
\left\langle\sigma_{\mathrm{V}}\right\rangle_{\text {ioniz }} & =\left\langle\sigma_{\mathrm{V}}\right\rangle_{\mathrm{cx}}=3.5 \times 10^{-14} \mathrm{~m}^{3} / \mathrm{sec}
\end{aligned}
$$

The results are summarized in Figs. 1 and 2. In Fig. 1 we have taken $P_{\mu}=5 \times 10^{-3}$ watts $/ \mathrm{cm}^{3}$ (roughly one fifth the microwave power density in EBT). Figure la shows the electron and ion temperatures and their ratio versus density and Fig. $1 \mathrm{~b}$ shows the confinement time and normalized ambipolar field versus density. Figure 2 shows the same curves assuming that $P_{\mu}=10^{-2} \mathrm{~W}^{\prime} \mathrm{cm}^{-3}$. These curves predict the existence of equilibria in reasonable agreement with experimental observations 


$$
\begin{gathered}
\mathrm{n} \approx 4 \times 10^{12} \mathrm{~cm}^{-3} \\
50 \mathrm{eV} \approx \mathrm{T}_{\mathrm{i}} \approx 90 \mathrm{eV} \\
150 \mathrm{eV} \approx \mathrm{T}_{\mathrm{e}} \approx 300 \mathrm{eV}
\end{gathered}
$$

and $\tau$ a few tens of milliseconds. The higher microwave power absorption gives somewhat better agreement. There is some experimental evidence that e $/ \mathrm{T}=0(1)$, which is also consistent with these results. The upper bound on density is presumably due to microwave cutoff.

There are no a cceptable equilibria corresponding to the lower density portion of the scales shown. It is interesting to speculate that this might be related to the observed sharp transition between the relatively high density quiescent $\mathrm{T}$-mode and the low density highly fluctuating M-mode as the fill density is decreased.

Note that the electron and ion temperatures increase with density and that the electric field and temperature ratio tend towards the collisionless limit of Eqs. (23) and (25). It appears from these calculations that present EBT operation is in a transitional regime to collisionless operation. 


\section{SUMMARY}

We have presented a simple neoclassical point model which is in reasonable agreement with experimental observations of power balance. We assumed that the dominant electron losses are neoclassical, and equated the neoclassical expressions for $\tau_{i}$ and $\tau_{e}$ to determine a self-consistent, ambipolar field which is then used to calculate power balance. An encouraging feature of the numerical ressults is that the temperatures and confinement times increase with density indicating an approach to a collisionless regime. If this regime can be reached the analysis predicts the very favorable density scaling $T_{e} \sim n^{4}$, $\tau \sim \dot{n}^{5}$ :

Finally we emphasize that scaling arguments based on $\tau\left(\mathrm{T}_{\mathrm{e}}, \mathrm{T}_{\mathrm{i}}\right.$, n) are consequences of neoclassical loss rates, and would be expected to be valid only in the absence of substantial plasma turbulence. Scaling arguments based on the relation between $\mathrm{I}_{\mathrm{e}}, \mathrm{I}_{\mathrm{i}}$ and the microwave power input $\mathrm{P}_{\mu}$ are peculiar to the particle heating scheme employed in EBT which channels the total energy input through the electrons. Other heating schemes, e.g. ion beam heating, will follow different scaling laws. 


\section{ACKNOWLEDGEMENTS}

We are grateful to R. A. Dandl for suggesting this problem and for many helpful discussions of the experimental results as well as in formulating a precursor to this theory. Three of us (CLH, EFJ AND DAS) would like to acknowledge helpful discussions with R. A. Dory, E. G. Harris, H. C. Howe, and N. H. Lazar. We would also like to thank S. E. Attenberger, D. L. Kaplan, J. F. Roberts and A. L. Sulton for help in the numerical computations. We acknowledge the hospitality of Dr. John Clarke during the many SAI visits to ORNL. 


\section{REFERENCES}

1. R. A. Dandl, H. O. Eason, G. E. Guest, C. L. Hedrick, H. [kegami and D. B. Nelson, in Plasma Physics and Controlled Nuclear Fusion Research (Proc. 5th Int. Conf. Tolryo, 1871) II , IAEA, Vienna, 141 (1975).

2. L. M. Kovrizhnykh, Sov. Phys. JETP 29 , 475 (1969).

3. E. G. Harris, private communication.

4. N. A. Krall and A. W. Trivelpiece, principles of plàsmā Physics (McGraw-Hill, New York, 1973). 


\section{FIGURE CAPTIONS}

Figure 1. (a) Electron and ion temperatures and their ratio

$\left(\mathrm{T}_{\mathrm{e}} / \mathrm{T}_{\mathrm{i}}\right)$ versus density assuming $\mathrm{F}_{\mathrm{i}}=5 \times 10^{-3} \mathrm{~W} / \mathrm{cm}^{3}$.

(b) Ambipolar confinement time and normalized electric field versus density.

Figure 2. Same as Figure 1 but with $\mathrm{P}_{\mu}=10^{-2} \mathrm{~W}^{\prime} \mathrm{cm}^{3}$. 


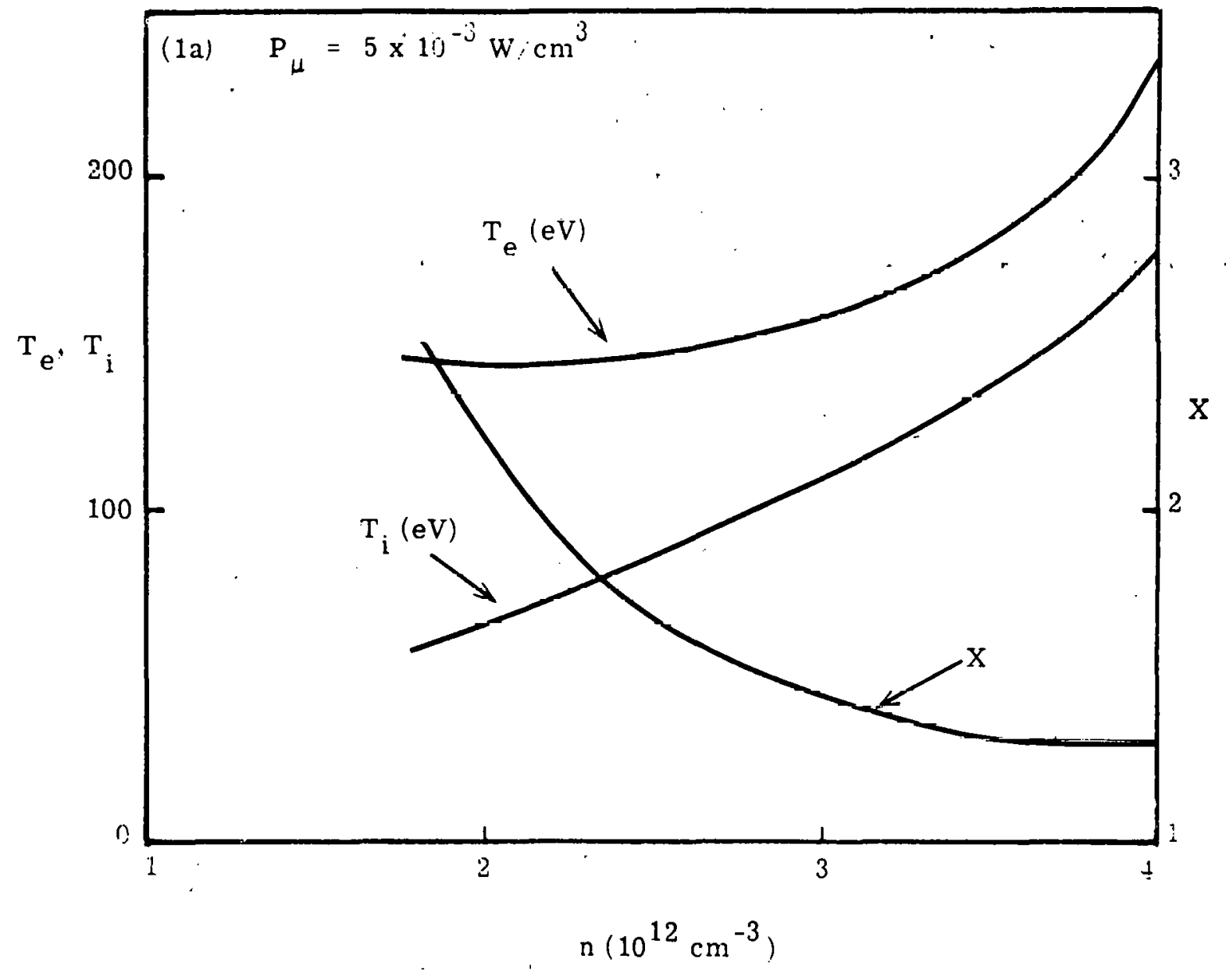

Figure la 


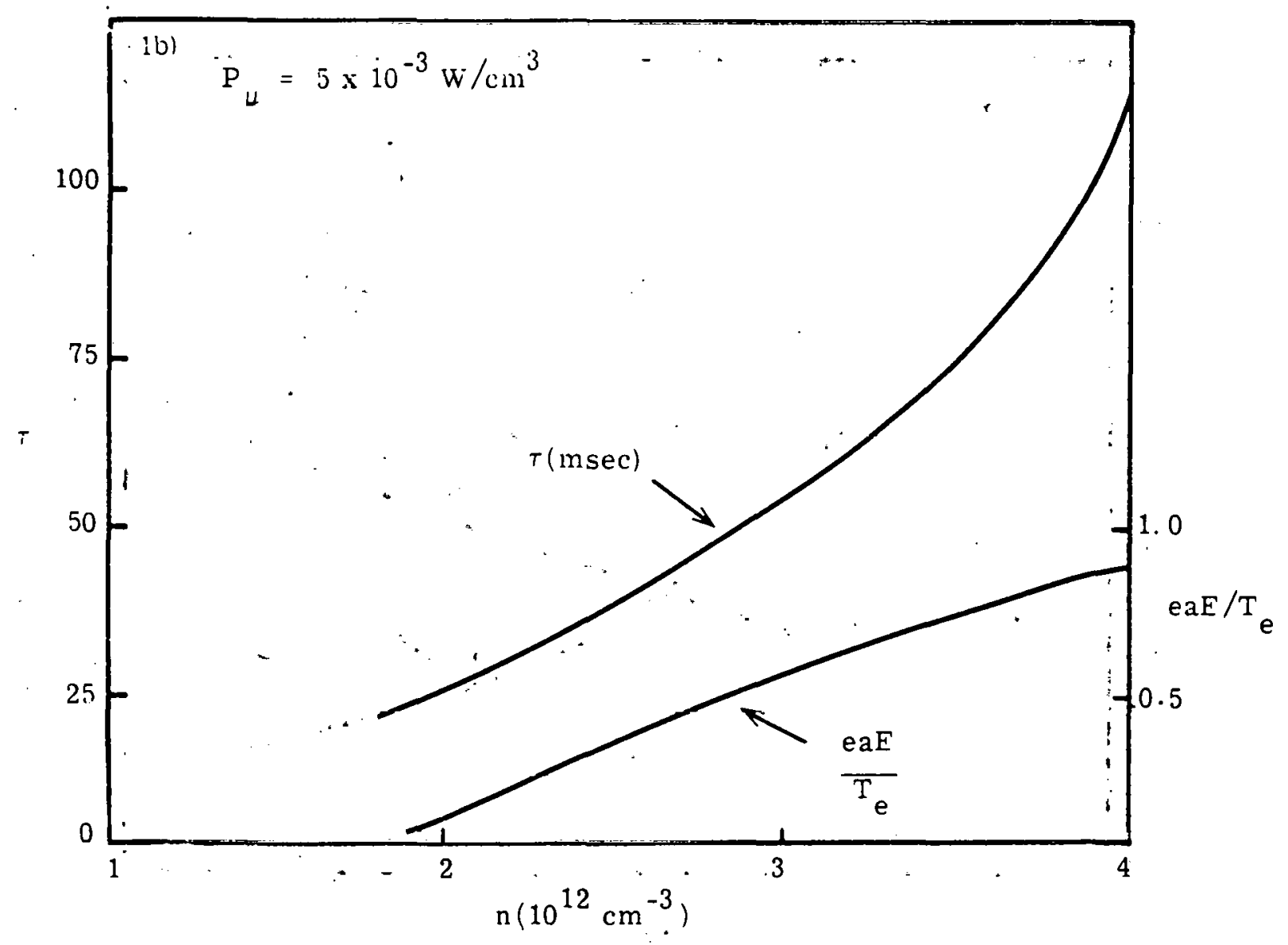

Figure ib 


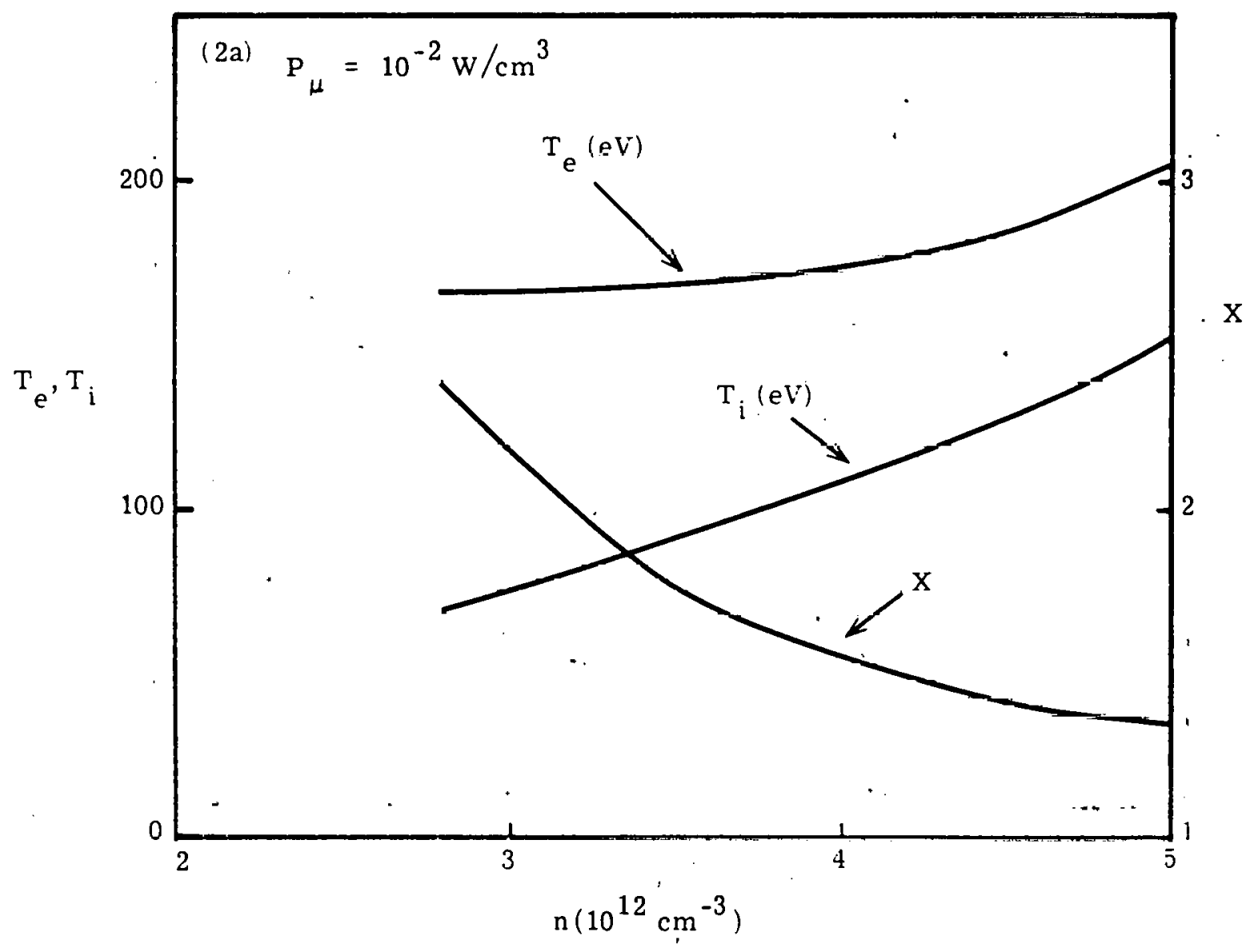

Figure 20 


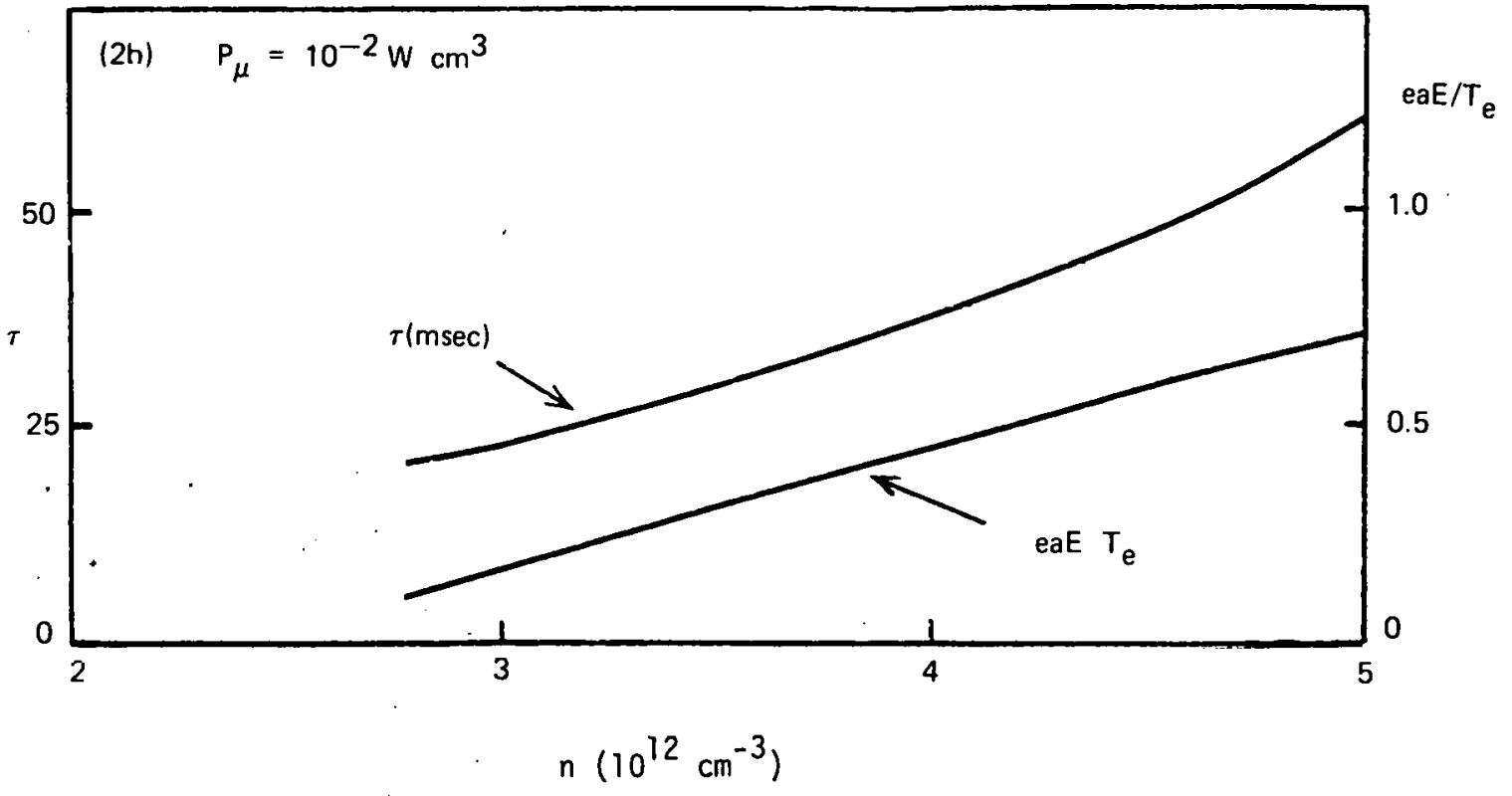

Figure 2b 


\section{THIS PAGE \\ WAS INTENTIONALLY \\ LEFT BLANK}




\section{INTERNAL DISTRIBUTION}

1. J. D. Callen

2. J. F. Clarke

3. R. A. Dory

4. G. G. Kelley

5. 0. B. Morgan

6. M. W. Rosenthal

7-31. C. L. Hedrick

32-34. Laboratory Records

35. Laboratory Records, ORNL - RC

36. Y-12 Document Reference Section

37-38. Central Research Library

39. Fusion Energy Division Library

40. Fusion Energy Division Reports Office

41. ORNL Patent Office

\section{EXTERNAL DISTRIBUTION}

42. Plasma Physics Library, Plasma Physics Laboratory, Princeton Univ., Forrestal Campus, P.0. Box 451, Princeton, NJ 08540

43. Controlled Thermonuclear Research Library, Lawrence Livermore Laboratory, P.0. Box 808, Livermore, CA 94550

44. Q Division Library, c/o F. L. Ribe, Los Alamos Scientific Laboratory, P.0. Box 1663, Los Alamos, NM 87544

45. Controlled Thermonuclear Research Library, c/o Weston M. Stacey, Jr., Argonne National Laboratory, 9700 S. Cass Ave., Argonne, IL 60439

46. CTR Computer Center, c/o Dr. John Killeen, Lawrence Livermore Laboratory, P.0. Box 808, Livermore, CA 94550

47. Librarian, Culham Laboratory, U.K. Atomic Energy Authority, Abingdon, 0xon, 0x14 3DB, United Kingdom

48. Ruth Lengye, Bibliothek, Max-Planck Institut für Plasmaphysik, 8046 Garching bei München, Federal Republic of Germany

49. Library, Centre de Recherches en Physique des Plasmas, 21 Avenue des Bains, 1007, Lausanne, Switzerland

50. A. M. Dupas, Documentation S.I.G.N., Department de la Physique du Plasma et de la Fusion Controlée, Association EURATOM-CEA sur 1a Fusion, Centre d'Etudes Nucléaires, BP 85 Centre Du TRI 38041 Grenoble Cedex (France)

51. Bibliothèque, Service du Confinement des Plasmas, C.E.A., B.P. No. 6, 92, Fontenay-aux-Roses (Seine) France

52. Library, International Centre for Theoretical Physics, Trieste, Italy

53. Library, Laboratorio Gas Tonizzati, Frascati, Italy

54. V. E. Ivanov, Physical-Technical Institute of the Ukranian Academy of Sciences, Sukhumi, U.S.S.R.

55. L. M. Kovrizhnikh, Lebedev Institute of Physics, Academy of Sciences of the U.S.S.R., Leninsky Prospect 53, Moscow, U.S.S.R.

56. Thermonuclear Laboratory, Kurchatov Institute of Atomic Energy, 46 Ul itsa Kurchatova, P.0. Box 3402, Moscow, U.S.S.R.

57. Library, Inst. for Plasma Physics, Nagoya Univ., Nagoya, Japan 464 
58. Library, FOM-Institut voor Plasma-Fysica, Rijnhuizen, Jutphaas, Netherlands

59.. Plasma Physics Group, Department of Engineering Physics, Australian National University, P.0. Box 4, Canberra A.C.T. 2600, Australia

60. Thermonuclear Library, Japan Atomic Energy Research Institute, Tokai, Naka, Ibaraki, Japan

61. Dr. D. G. McAlees, Exxon Nuclear Co., Inc., Research \& Technology Laser Enrichment Department, 2955 George Washington Way, Richland, WA 99352

62. CTR Reading Room, c/o Prof. D. W. Kerst, Dept. of Physics, Sterling Hal1, Univ. of Wisconsin, Madison, WI 53706

63. CTR Reading Room, c/o Prof. I. B. Bernstein, Yale Univ., 200 Mason Laboratory, New Haverı, CT 06510

64. Center for Plasma Physics and Thermonuclear Research, c/o D. W. Ross, Physics Dept., Univ. of Texas, Austin, TX 78712

65. CTR Reading Room, c/o Prof. B. D. Fried, Physics Dept., Univ. of California, Los Angeles, CA 90024

66. CTR Reading Room, c/o Prof. David C. Montgomery, Physics \& Astronomy Dept., Univ. of Iowa, Iowa City, IA 52240

67. Magneto-Fluid-Dynamics Library, c/o Dr. Harold Grad, Courant Inst. of Math. Sci., New York Univ., 251 Mercer St., New York, NY 10012

68. CTR Reading Room, c/o Prof. Allan N. Kaufman, Physics Dept., Univ. of California, Berkeley, CA 94720

69. Dr. David A. Dingee, Fusion Programs, Batelle-Northwest, Batelle Boulevard, Richland, WA 99352

70. CTR Reading Room, c/o Prof. C. S. Liu, Dept. of Physics and Astronomy, Univ. of Maryland, College, MD 20742

71. CTR Reading Room, c/o Prof. T. Kammash, 103 Research Admin. Bldg., N. Campus, Univ. of Michigan, Ann Arbor, MI 48105

72. CTR Reading Room, c/o Dr. Ravi N. Sudan, Phillips Ha11, Cornell Untv., I litiac.a, NY 14850

73. Prof, Marshali N. Rosenbluth, Institute for Advanced Study, Prince= ton, NJ 08540

74. CTR Reading Room, c/o Prof. R. Gross, Plasma Research Lab., Columbia Univ., New York, NY 10027

75. CTR Reading Room, c/o Prof. Roy Gould, California Inst. of Tech., M.S. 116-81, Pasadena, CA 91125

76. Dr. Nicholas A. Krall, Science Applications, Inc., P.0. Box 2354, 1200 Prospect St., La Jolla, CA 92037

77. CTR Reading Room, c/o Dr. Jay P. Boris, Plasma Physics, Naval Research Laboratory, Washington, DC 20390

78. Professor A. Simon, Dept.. of Mechanical \& Aerospace Sciences, University of Rochester, Rochester, NY 14627

79. CTR Library, c/o Dr. Alan F. Haught, United Technologies Research Labs, East Hartford, CT 06108

80. Dr. H. K. Forsen, Exxon Nuclear Co., Inc. 777-106th Avenue, NE, C-000777, Bellevue, WA 98009

81. Dr. George Vahala, Physics Dept., College of Wilitiam \& Mary, Williamsburg, VA 23185

82. Dr. Robert E. Price, Division of Magnetic Fusion Energy, G-234, Energy Research and Development Administration, Washington, D. C. 20545 
83. Dr. R. C. Davidson, Division of Magnetic Fusion. Energy, G-234, Energy Research and Development Administration, Washington, D. C. 20545

84. Dr. Oscar P. Manley, Division of Magnetic Fusion Energy, G-234, Energy Research and Development Administration, Washington, D. C. 20545

85. Mr. E. E. Kintner, Division of Magnetic Fusion Energy, G-234, Energy Research and Development Administration, Washington, D. C. 20545

86. Dr. L. D. Pearlstein, L-388, Lawrence Livermore Laboratory, P.0. Box 808, Livermore, CA 94550

87. Dr. J. P. Friedberg, Los Alamos Scientific Laboratory, Los Alamos NM 87544

88. Dr. David J. Rose, Dept. of Nuclear Engineering, MIT, Cambridge, MA 02139

89. Dr. Gareth E. Guest, General Atomic Co., P.0. Box 81608, San Diego, CA 92138

90. Dr. Claude Mercier, Service du Theorie des Plasmas, Centre d'Etudes Nucleaires, Fontenay-aux-Roses (Seine) France

91. Dr. J. B. Taylor, Culham Laboratory, UKAEA Abingdon, Oxon, 0X14 3DB, United Kingdom

92. Dr. D. Pfirsch, Institute for Plasma Physics, 8046 Garching bei München, Federal Republic of Germany

93. Dr. V. D. Shafranov, I. V. Kurchatov Inst. of Atomic Energy, 46 Ulitsa Kurchatova, P.0. Box 3402 , Moscow, U.S.S.R.

94. Dr. A. Rogister, Institute for Plasma Physics, KFA, Postfach 1913, D-5170, Jülich 1, Federal Republic of Germany

95. Dr. J. G. Cordey, Culham Laboratory, UKAEA, Abingdon, Oxon, 0X14 3DB, United Kingdom

96. Dr. David Baldwin, L-388, Lawrence Livermore Lab., P.0. Box 808, Livermore, CA 94550

97. CTR Reading Room, c/o Prof. Bruno Coppi, Dept. of Physics, MIT, Cambridge, MA 02139

98. Dr. Harold P. Furth, Princeton Plasma Physics Lab., Princeton Univ., P.0. Box 451, Princeton, NJ 08540

99. Dr. Paul H. Rutherford, Princeton Plasma Physics Lab., Princeton Univ., Princeton, NJ 08540

100. Dr. Herbert H. Woodson, Dept. of Electrical Engineering, Univ, of Texas, Austin, TX 7812

101. Research \& Technical Support Div., Oak Ridge Operations, Energy Research and Development Administration, P.0. Box E, Oak Ridge, TN 37830

102-128. Tech. Information Center, Oak Ridge Operations, Energy Research and Development Administration, P.0. Box 62, Oak Ridge, TN 37830 